\begin{abstract}
Austerity measures implemented by the UK Coalition government have had a negative impact on disabled people (Cross 2013). This article utilises the resource dependence theory to explore the challenges national disability sport organisations (NDSOs) have faced in their attempts to achieve growth, whilst discussing some of the tactics used to overcome these challenges. Secondary quantitative data from the 2011-2015 NDSO accounts was analysed, which suggests increased income has been accompanied by increased cost, with fluctuations between surpluses and deficits across the financial years. Funding from Sport England, the government body for grassroots sport in England, was either awarded for the first time or increased. Nine in-depth interviews were conducted with senior managers from seven NDSOs, the English Federation of Disability Sport, and Sport England. It was found austerity presented challenges for the NDSOs in accessing charitable grants and funding, and that some disabled people were fearful of losing their disability benefits if they were seen to be active. The management of relationships with national governing bodies and county sport partnerships was also a challenge. The formation of alliances, the building up of financial reserves, and the generation of knowledge, have been some of the tactics used by the NDSOs in the management of their resources. This research highlights how some NDSOs have achieved growth amid an uncertain economic backdrop, and how these organisations have managed their scarce resources.
\end{abstract}




\title{
The organisational performance of National Disability Sport Organisations during a time of austerity: A resource dependence theory perspective
}

\begin{abstract}
Austerity measures implemented by the UK Coalition government have had a negative impact on disabled people (Cross 2013). This article utilises the resource dependence theory to explore the challenges national disability sport organisations (NDSOs) have faced in their attempts to achieve growth, whilst discussing some of the tactics used to overcome these challenges. Secondary quantitative data from the 2011-2015 NDSO accounts was analysed, which suggests increased income has been accompanied by increased cost, with fluctuations between surpluses and deficits across the financial years. Funding from Sport England, the government body for grassroots sport in England, was either awarded for the first time or increased. Nine in-depth interviews were conducted with senior managers from seven NDSOs, the English Federation of Disability Sport, and Sport England. It was found austerity presented challenges for the NDSOs in accessing charitable grants and funding, and that some disabled people were fearful of losing their disability benefits if they were seen to be active. The management of relationships with national governing bodies and county sport partnerships was also a challenge. The formation of alliances, the building up of financial reserves, and the generation of knowledge, have been some of the tactics used by the NDSOs in the management of their resources. This research highlights how some NDSOs have achieved growth amid an uncertain economic backdrop, and how these organisations have managed their scarce resources.
\end{abstract}




\section{Introduction}

Following the UK General Election in 2010 and the formation of a Coalition government between the Conservatives and the Liberal Democrats, the Coalition set about cutting the national debt through the imposition of austerity (Blyth 2013). Austerity is “.... form of voluntary deflation in which the economy adjusts through the reduction of wages, prices, and public spending to restore competitiveness, which is (supposedly) best achieved by cutting the state's budget, debts, and deficits" (Blyth 2013, p. 2). Some economic commentators, however, have suggested austerity makes little economic sense as a way of producing growth (Blyth 2013; Krugman 2015), and that the primary reason the Coalition introduced austerity was to shrink the size of the welfare state, rather than cut the national debt (Krugman 2015). Austerity has been labelled a dangerous economic idea by Blyth (2013) for three principal reasons: previous evidence demonstrates austerity does not produce economic growth; the poorest in society are often the worst hit by budget cuts; and a fallacy of composition is present when governments decide to cut their budgets at the same time with no nation able to address the shortfall in spending.

One of the groups most affected by austerity is disabled people. When austerity is implemented it often results in the poorest members of society paying (in both a literal and figural sense) for the mistakes of the elite (Blyth 2013). The Coalition government's reforms to disability benefits have had a substantial impact, with an estimated 1.25 million people expected to lose some if not all of their disability benefits (Beatty and Fothergill 2015). The 'reform' of the disability benefits system by the Coalition government and the current Conservative government has had a decidedly negative impact on the daily lives of disabled people (Cross 2013). In fact, the UK was the first country to be under investigation for potential violation of disabled people's right to live independently and to an adequate standard of living (Pring 2015). Cross (2013) argued that the actions of the Coalition 
government were symptomatic of a government which did not value the welfare of disabled people. Following the introduction of the Workplace Capability Assessment (WCA), despite being discredited by disability activists and parliamentarians, 10,600 disabled people died within six weeks of their WCA, with at least a further thirty committing suicide after the decision to take their benefits away had been made (Cross 2013). The closure of the Independent Living Fund and the cap placed on the benefits that individual households are able to claim, have produced negative impacts on the daily lives of disabled people (Cross 2013).

Disabled people have received a negative portrayal in the media (Briant et al. 2013; Crow 2014; Pappous et al. 2011). The characterisation of disabled people as scroungers who are cheating the system has been a common theme in the media coverage of disabled people (Briant et al. 2013; Crow 2014). The evidence for these claims are often inaccurate and are frequently misleading (Briant et al. 2013; Wood 2012). It has been suggested that the concerted negative portrayal of disabled people has been a way of garnering support for the changes to the disability benefits system brought in by the Coalition government (Briant et al. 2013; Wood 2012). Briant et al. (2013) argue that if the negative media coverage of disabled people continues unabated it could further entrench the oppression disabled people face in society, reversing some of the positive progress that had been made in recent years.

\section{The impact of austerity on sport}

Research into the impact of austerity on sport provision is sparse; few studies have investigated this topic empirically (Parnell et al. 2015). During the Coalition government, local authorities have increasingly outsourced the use of their sport facilities in a bid to save money (King 2014; Parnell et al. 2015). This is hardly surprising as local councils have been one of the areas of government hit the hardest by the Coalition's budget cuts (Lowndes and 
Gardner 2016). Adopting a resource dependent theoretical approach, Walker and Hayton (2016) discussed how a third sector disability sports organisation, Greenbank disability sports academy, has been able to navigate its environment during austerity. The authors discovered Greenbank was able to retain a reasonable level of autonomy because the organisation was not overly dependent on public funding. The organisation has been able to support its sport development initiatives with the areas of the organisation that provide profit, whilst still maintaining a commitment to the overall mission objectives of the organisation (Walker and Hayton 2016).

Disabled people have seen their disposable income and health negatively affected because of the austerity policies of the Coalition government in the UK (Cross 2013; Wood 2012). With local authorities being one of the areas of government to face the harshest financial implications of austerity (Lowndes and Gardner 2016), sport services offered by local authorities appear to be increasingly outsourced to private enterprises (King 2014; Parnell et al. 2015). How, then, have charitable organisations that offer sporting services for disabled people in England fared during the Coalition government and the current Conservative government? Walker and Hayton (2016) provide an insight into a case-study of one such organisation, but the findings from their research is limited to one organisation in a specific part of the country. This article will investigate the performance of seven of the eight organisations recognised as being a national disability sport organisation (NDSO). What challenges have the NDSOs faced in their attempts to meet their organisational objectives of more disabled people participating in sport? What tactics have the NDSOs adopted to meet their objectives? These questions are the foundation of the research reported in this paper. To adequately address the research questions, the resource dependence theory (Pfeffer and Salancik 2003) will frame the presentation and discussion of the research findings.

\section{Theoretical framework: Resource Dependence Theory (RDT)}


Resource dependence theory posits that the survival and actions of an organisation are influenced by its access to scarce resources in its environment and the dependency of the organisation on these resources (Pfeffer and Salancik 2003). Organisations do not have complete control over the resources they need to survive, necessitating interaction with their environment to procure the resources needed for the organisation's continued existence, creating a situation of dependency of the organisation on other interest groups for valued resources (Pfeffer and Salancik 2003; Ulrich and Barney 1984). RDT posits that organisations are therefore motivated to obtain resources that reduces its dependency on other organisations (Pfeffer and Salancik 2003; Ulrich and Barney 1984). Pfeffer and Salancik (2003) outlined three factors thought to be important in understanding the nature of dependence of one organisation on another. First, the resource should be of importance in terms of the organisation's function and survival. Second, the degree to which the interest group is able to distribute and use the resource compared to that of the dependent organisation. Finally, the availability of alternatives for the dependent organisation, or the nature of control over the utilisation of the resource by the interest group.

Essentially, RDT focuses on the power relationships between organisations in the exchange of resources (Casciaro and Piskorski 2005; Ulrich and Barney 1984). Asymmetry in the power relations between organisations is what creates dependence (Pfeffer and Salancik 2003). Emerson's (1962) theory of power-dependence relations forms the basis of the RDT (Hillman et al. 2009; Malatesta and Smith 2014). Emerson posited that the power of Actor A over Actor B is the inverse of the dependence of Actor B on Actor A (Casciaro and Piskorski 2005). Power thus needs to be treated as a dyad, and the power and dependence of either actor on each other must be considered and accounted for at the same time when considering the power relationship between two parties (Casciaro and Piskorski 2005; Emerson 1962). Using Emerson's (1962) conception of power relations, Casciaro and Piskorski (2005) 
proposed a revision to RDT, criticising the RDT and its failure to simultaneously consider the role of power imbalance (the differential of power between two actors) and mutual dependence (the total level of dependence existing between the actors). This is because there can be varying levels of mutual dependence for a given value of power imbalance and viceversa (Casciaro and Piskorski 2005). Casciaro and Piskorski (2005) found that power imbalance limited the likelihood of mergers and acquisitions taking place, because the powerful organisation would be unlikely to be willing to cede its dominant position over the dependent organisation, but that mutual dependence is likely to facilitate mergers and acquisitions occurring.

The RDT is a useful theoretical framework for analysing the development of non-profit organisations, such as NDSOs. As non-profit organisations, NDSOs navigate uncertain and limited funding sources to drive their operations. Indeed, non-profit organisations are reliant on government funding, charitable donations and funds, thus are exposed to changes in the flow of resources and its environment (Carroll and Stater 2008). RDT has been used to research non-profit organisations in a variety of different contexts (e.g. Bingham and Walters 2013; Froelich 1999; Walker and Hayton 2016), thus the RDT is well suited to exploring the challenges of organisations dependent on external resources in order to survive. In addition, NDSOs are in a fragmented and complex sector (Thomas and Guett 2014), thus power imbalances and mutual dependence between actors frequently occur. RDT, and its focus on power relationships, provides a lens through which the activities of the NDSOs can be analysed. RDT is thus an appropriate theoretical framework to explore how NDSOs have coped with an uncertain environment caused by austerity measures.

\section{What is a National Disability Sporting Organisation?}


NDSOs are national sporting organisations representing the interests of specific impairment groups (Table 1). For example, Cerebral Palsy Sport focus their resources on athletes ${ }^{1}$ who have cerebral palsy, whereas British Blind Sport would be focused on athletes with visual impairments. An NDSO's primary role is to facilitate and enable other organisations to deliver sport, either mainstream or adapted versions of the sport, for the athletes they represent. Delivery of sport participation is not supposed to be an intended feature of the organisation's activities. NDSOs often work closely with national governing bodies (NGBs) and county sport partnerships (CSPs) in the delivery of sport for their consumers. The role of an NDSO is, thus, of a strategic nature, and should not involve much delivery of sport. NDSOs are experts in their field, in terms of insight and knowledge, whereas providers of sport, such as NGBs, are the experts who know how to deliver their sport. Sport England provide funding for the NDSOs in three-year cycles and through the availability of individual grants for projects. The English Federation of Disability Sport (EFDS) also work with the NDSOs to generate insight and resources about disability sport, and to facilitate sport participation opportunities for athletes. To view the NDSOs as being the same would be misguided, as each NDSO is different and at different stages of their organisational development.

Table 1: An overview of the interviewed NDSOs

\begin{tabular}{|c|c|c|c|}
\hline$\underline{\text { NDSO }}$ & $\begin{array}{c}\underline{\text { Year }} \\
\text { founded }\end{array}$ & $\begin{array}{c}\underline{\text { Impairment }} \\
\text { focus }\end{array}$ & $\underline{\underline{\text { Funding received from Sport }}}$ \\
\hline British Blind Sport & 1976 & Visual & England \\
(BBS) & & & $2011-2014: £ 290,204$ \\
\hline Cerebral Palsy Sport & 1968 & Cerebral Palsy & $2011-2014: £ 183,409$ \\
\hline
\end{tabular}

1 'Athletes' refer to disabled people participating in sport at the grassroots level. 


\begin{tabular}{|c|c|c|c|}
\hline (CP Sport) & & & $2014-2017: £ 265,882$ \\
\hline $\begin{array}{l}\text { Dwarf Sports } \\
\text { Association UK } \\
\text { (DSAuk) }\end{array}$ & 1993 & $\begin{array}{l}\text { Dwarfism and } \\
\text { restricted growth }\end{array}$ & $\begin{array}{l}2011-2014: £ 193,615 \\
2014-2017: £ 217,532\end{array}$ \\
\hline LimbPower & 2009 & Amputees & $2014-2017: £ 210,437$ \\
\hline $\begin{array}{c}\text { Special Olympics } \\
\text { Great Britain } \\
\text { (SOGB) }\end{array}$ & 1978 & Learning & $\begin{array}{l}2014-2017: £ 401,153 \text { (this figure is } \\
\text { for the English Learning Disability } \\
\text { Sports Alliance, which includes } \\
\text { Mencap Sport) }\end{array}$ \\
\hline $\begin{array}{c}\text { UK Deaf Sport } \\
\text { (UKDS) }\end{array}$ & 2003 & $\begin{array}{l}\text { Deafness and } \\
\text { hard of hearing }\end{array}$ & $\begin{array}{l}2011-2014: £ 281,974 \\
2014-2017: £ 365,872\end{array}$ \\
\hline WheelPower & 1948 & $\begin{array}{l}\text { Spinal cord } \\
\text { injury }\end{array}$ & $\begin{array}{l}2011-2014: £ 196,279 \\
2014-2017: £ 238,063\end{array}$ \\
\hline
\end{tabular}

Source: This table was created using information from the NDSO interviews and Thomas and Smith (2009). Sport England funding was retrieved from the English Federation of Disability Sport (2014); Sport England (2011).

\section{Methods}

\section{Secondary data}

First, the authors obtained the financial accounts for the NDSOs from the publically available Charity Commission website for the financial year ends 2011 to 2015. This time-period was 
chosen to ensure there was no missing data for any of the NDSOs, ${ }^{2}$ and to reflect the majority of the time in office of the UK Coalition government. The purpose of the secondary document analysis was to gain an understanding of the NDSOs' finances, specifically by reviewing their year on year income and expenditure for the time period reviewed. The qualitative elements of the financial accounts were read to understand any themes relevant to the use of the RDT in the data analysis phase. Insights produced from the analysis of the financial accounts were generated by the lead author, with the co-author reviewing the analysis.

\section{Primary data}

\section{Participants}

For the qualitative component of this study, semi-structured interviews were conducted with seven NDSO organisations. The one NDSO not to be included in the research was Mencap Sport, as it was not possible for the lead author to interview a member of staff at the organisation. The authors argue, however, that as SOGB has been included in the research, and they are one of the two organisations that form the English Learning and Disability Sports Alliance, representation from all NDSOs was obtained. In addition to the NDSO interview data, the views of two national sport organisations (NSOs), Sport England and the EFDS, were sought in order to gain insight from these integral national sports organisations. The individual interviewed from Sport England was a member of the four-strong disability

\footnotetext{
${ }^{2}$ There is some variance in the financial year-ends reporting for the NDSOs. The NDSOs did not all have financial accounts publically available to view on the Charity Commission website for the full duration of the Coalition government of 2010-2015.
} 
team operating within Sport England ${ }^{3}$, whilst the EFDS individual was a senior manager from the organisation. It is important to point out that the perspectives of the NGBs and CSPs, critical resources for the NDSOs, have not been included in this research. Thus, the findings are predominately from the views of the dependent organisations, NDSOs, rather than from the NGBs or CSPs themselves.

\section{Procedure}

The research reported in this paper was borne out of a wider research project focusing on the grassroots sport participation legacy of the 2012 Paralympic Games. The RDT framework was chosen and operationalised at the analysis stage of the research. All organisations were purposively included in our sample and the relevant individual was selected based on their job role following a review of the organisation's website. For some of the NDSOs and one NSO, already interviewed participants or employees at the target organisation recommended a specific individual who would be best placed to address the aims of the research. Contact was made by the lead author in all instances and the primary method of communication was by email. The email outlined the details of the research and attached a participant information sheet and consent form. Only when agreement to participate was provided in writing and a consent form signed and dated, did the interview take place. All participants were interviewed by the lead author. Seven of the nine interviews were conducted face-to-face, with the other two interviews conducted using Skype, due to geographic and financial restrictions. The first interview was held in July 2015 with the last data collection taking place in May 2016. Interviewees were afforded the opportunity to clarify the interpretation of the interviewer at the end of the interview, and to add any salient points that had been omitted

3 Correct as of March 2016, when the interview with the participant from Sport England took place. 
or needed to be clarified. This tactic, recommended by Brinkmann and Kvale (2015); Kvale (2007), ensured each interviewee was given the option to assess the interpretation of the interviewer, increasing the trustworthiness of the findings. Each interview was recorded using a Dictaphone and transcribed verbatim.

\section{Data analysis}

The qualitative data was coded using first-cycle coding processes recommended by Saldaña (2016), with in vivo and initial coding used to create a list of codes. In vivo coding enabled the participant voice to be highlighted, whilst initial coding helped the lead author to interrogate the themes of the data in finer detail (Saldaña 2016). Some transcripts were also coded using holistic and descriptive coding techniques. Holistic coding provided a general overview of the themes of the interview, whereas descriptive coding identified the topics that were discussed during the interviews (Saldaña 2016). Holistic and descriptive coding was discontinued for the last two interview data as saturation of codes from these processes had been reached. The final list of codes was then categorised and placed into themes. A further data reduction technique was to create a table providing an overview of each respondent on key questions guiding the research. This included challenges faced by the NDSOs, influences of the external environment on the NDSO's operations, and the development of the NDSO as an organisation. Throughout the transcribing and data analysis process, analytic memoing was used in order to detail conceptual thoughts and note patterns about the data (Saldaña 2016). The memos were reviewed and placed into themes alongside the categorised codes. Coding was undertaken by the lead author as well as identification of emergent themes from the data. The themes were then reviewed and verified during face to face discussions in meetings between the first and second author. The dialogic exchange and critical discussions enabled the final refinement of the generated themes to occur. 


\section{Secondary analysis findings}

\section{Increased income has been accompanied by increased costs}

By the end of the 2015 financial year, all of the NDSOs had increased their total income since 2011, with the only exception being CP Sport (Table 2). The income received from Sport England has boosted the incomes of these NDSOs, and government funding is one of the more stable sources of revenue for a charity (Froelich 1999), but has left them vulnerable to being too dependent on this source of income generation (Bingham and Walters 2013; Carroll and Stater 2008).

All of the NDSOs have experienced at least one deficit in their financial year, with CP Sport and WheelPower recording four deficits out of the five financial years under review (Table 2). For some of the NDSOs, there have been some sudden movements from deficit to surplus or from surplus to deficits. The change from surplus to deficit and deficit to surplus from one financial period to the next may be a sign of the difficult economic backdrop in which the NDSOs have operated in, and the fluctuating nature of the grants and donations the NDSOs have been able to generate each year. All of the NDSOs have seen their expenditure on staffing costs increase and a significant number of the NDSOs have increased the number of staff $^{4}$ they have been able to employ since 2011. The increased number of staff indicates growth, as demand for the NDSO's services has increased, along with the workload of the NDSO. Special events run by the NDSOs have had positive and negative impacts on the finances of the NDSOs. SOGB, for example, saw their total income increase significantly in 2013 following the hosting of the National Summer Games, in which they were able to attract sufficient levels of sponsorship to self-fund the event (Special Olympics Great Britain 2016). CP Sport's hosting of the 2015 CP World Games was a financial failure for the organisation.

\footnotetext{
4 This refers to full-time members of staff only. Board members have not been included.
} 
Article accepted for publication in the International Journal of Sports Policy and Politics, 19/10/2017.

The event boosted the media coverage received, but cost more than it was budgeted for and income was less than expected (Cerebral Palsy Sport 2016). In addition, the hosting of the 2015 CP World Games impacted on CP Sport's ability to raise funds from other activities, as the organisation was focused on hosting and organising the event (Cerebral Palsy Sport 2016).

From this brief analysis of the 2011-2015 finances, it is clear that the NDSOs' income have increased, but so too has expenditure (Table 2). The NDSOs have all grown their income, albeit to varying degrees, and most of the NDSOs have increased their number of full-time employees working for the organisation. It is a challenge for the NDSOs to continue to increase their income and the services they offer, and to be able to cover the costs involved in growing the charity. A number of the NDSOs are dependent on grants for their voluntary income, specifically the grants awarded by Sport England, leaving them exposed to a drop or fall in the income received from Sport England. The environment has been challenging for the NDSOs to navigate, and there is much work for the NDSOs to do to continue to raise the funds from a diverse range of sources, if the organisational objectives are to accomplished. 


\section{Page 15 of 39 Accepted Manuscript.

Article accepted for publication in the International Journal of Sports Policy and Politics, 19/10/2017.

Table 2: NDSOs’ 2011-2015 year-end income, expenditure, and net income/expenses results

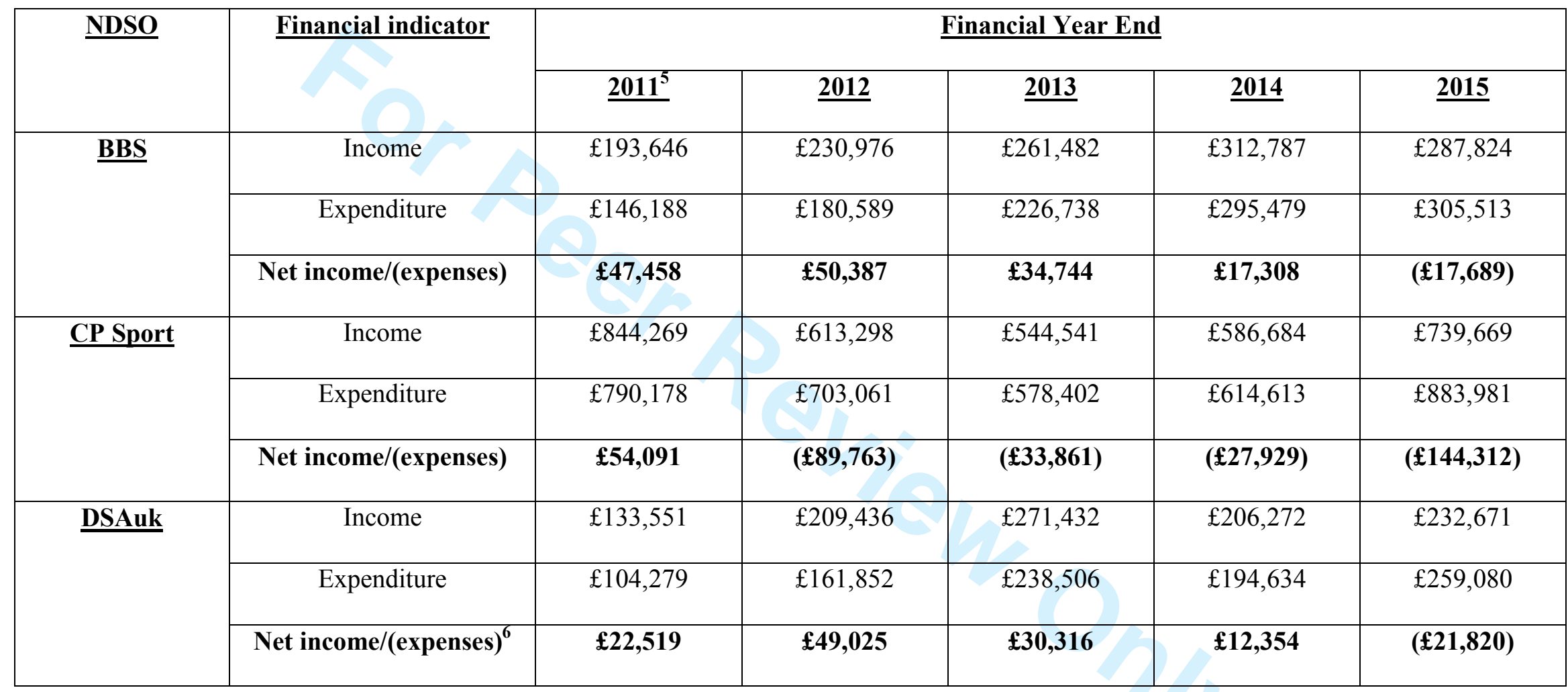

5 There are three different financial year-ends reported for the NDSOs. BBS, CP Sport, DSAuk, and SOGB have a financial year end of $31^{\text {st }}$

December. LimbPower has a financial year end of $30^{\text {th }}$ June. UKDS and WheelPower have a financial year end of $31^{\text {st }}$ March.

6 DSAuk's net income/(expenses) include non-cash payments or adjustments 


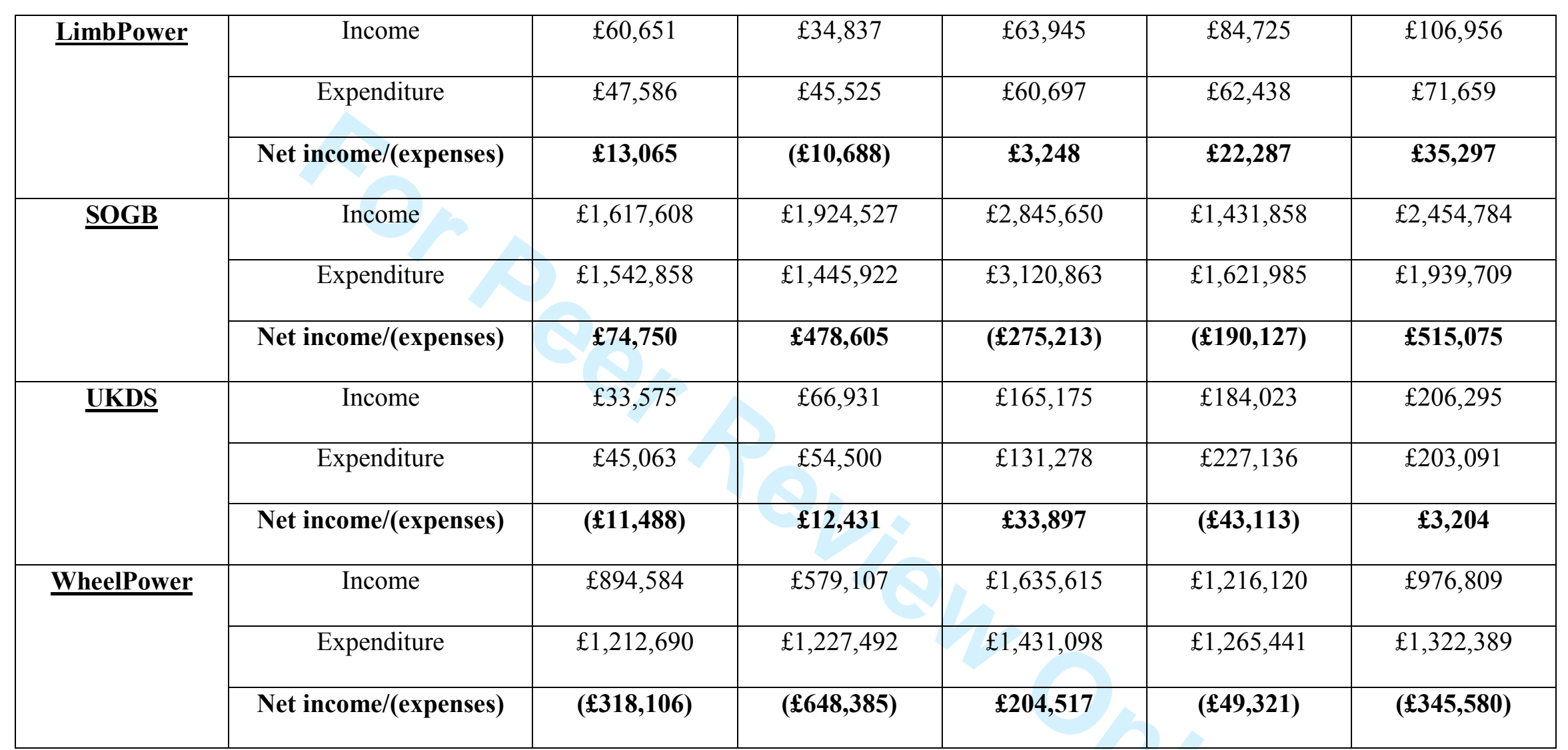

\footnotetext{
Sources: Charity Commission (n.d.) for all NDSOs except UK Deaf Sport; Information for UK Deaf Sport obtained from UK Deaf Sport (n.d.).
} 


\section{Primary findings}

This section of the paper will discuss the challenges faced by the NDSOs, followed by a discussion of some of the tactics used by the NDSOs to manage their resources. This section will conclude with a review of the role austerity has played on the organisational performance of the NDSOs.

\section{Growing incurs costs}

According to the RDT, the importance of the resource to the organisation is one of the important indicators of dependency (Pfeffer and Salancik 2003). The importance of a resource can be broken down into the magnitude of the exchange (the proportion of the resource accounting for the inputs or outputs of an organisation) and the criticality of the resource (how the absence of the resource impacts on the function of the organisation) (Pfeffer and Salancik 2003). Consistent with other studies into non-profit organisations (Froelich 1999; Walker and Hayton 2016), securing funding was one of the main challenges highlighted by the NDSOs:

It's a hard climate for fundraising out there. I think every charity is trying to chase the same pound. You have to be quite clear and quite clever, in terms of what funding you are going for, whether that's charitable foundations, trusts, or even community fundraising programme. (Respondent 1).

Challenges has been funding. It always will be; we're a charitable organisation. That will always be our number one challenge; making sure we're afloat. (Respondent 6).

As charities, NDSOs face constant pressure to raise enough funds to cover the operation of the charity and to meet its objectives. This was highlighted by one participant, who noted that 'the outlay from the charity is more every year, not less, and it's quite a challenge to fight that' (Respondent 4). By growing as a charity, this increases the costs incurred to keep the 
charity operating, placing a greater strain and importance on obtaining additional funds. Limited funding also restricts the ability of the NDSO to advise and influence organisations in the number of locations it would like to across the country, as most NDSOs 'haven't got the funding to have regional officers, so it's a lot harder for us' (Respondent 7). The activities of the NDSO is thus constrained by funding limitations.

Securing grants forms a significant proportion of the NDSOs' inputs and therefore access to funds can be considered to be of high magnitude and of critical importance for the NDSOs in their operations. Without the grants the NDSOs receive, the scale of the NDSOs' operations would be severely reduced and would negatively affect the chances of achieving growth. Indeed, some NDSOs face the prospect of reduced staff numbers due to the funding for the job role expiring. Without a replacement source of finance for these staff positions, the outputs of the business could be negatively affected:

At the moment we've 2 Regional Development Officers that work hand-in-hand with our volunteer's regions and help to grow that, and they've been funded out of some of the charity reserves [emphasis] at the moment, because we can't find charitable funding or money that will be able to sustain those. And without something cropping up...the 2 roles are going to be lost, so we're actually going to be shrinking back, not growing in employment. (Respondent 4).

The enhanced profile and status for disability sport as a result of the 2012 Paralympic Games has benefitted some of the NDSOs in being able to secure donations and funds for the organisation (Respondent 6). For example, one NDSO received a $£ 50,000$ donation from a celebrity edition of a game show, and that donation helped to stabilise the NDSO because 'that buffer hadn't been there previously' (Respondent 6). That donation was partly responsible for the NDSO being able to invest in a fundraising manager to further help the 
organisation diversify its income streams (Respondent 6). Despite funds and donations as a result of the improved status of disability sport, some of the NDSOs, to a strong degree, are dependent on the discretion of providers such as Sport England to maintain their current operations.

\section{NGBs and CSPs are critical resources for the NDSOs}

NDSOs are dependent on NGBs in delivering national sport participation opportunities for their target market. The NGBs, as a resource for the NDSO, can be considered to be of critical importance and high magnitude for the NDSOs' ambition to achieve their organisational objectives (Pfeffer and Salancik 2003). Access to these critical resources was constrained by approaches, which could be characterised as ableist, from most NGBs before the 2012 Paralympic Games. Indeed, it has been argued that ableist thinking is still present within the structures of UK grassroots sport (Brittain and Beacom 2016). Ableism describes the discrimination against disabled people that occurs because of a privileging and prioritisation of non-disabled perspectives and definitions of what is 'normal', which is judged commensurate with non-disabled experiences (Brittain and Beacom 2016; Wolbring 2012). Most NGBs, therefore, viewed sport from the perspective of non-disabled people, neglecting and devaluing sport participation opportunities for disabled people. Consequently, NGBs were 'not interested in anything else, absolutely not interested, with one or two notable exceptions, in doing anything around disability' (Respondent 2). This meant that NDSOs who attempted to engage with NGBs were ' .... knocking against closed doors because people were going, “well, we're not ready for this, we don't have to do it, we're not doing it", kind of thing' (Respondent 2). NDSOs were thus attempting to overcome ableist attitudes that permeated the sport sector prior to the 2012 Paralympics. This created asymmetry in power relations between the NDSOs and NGBs, with the role of NDSOs undervalued by most NGBs (Pfeffer and Salancik 2003). 
As per Brittain and Beacom (2016), the ableist structures within UK sport is evidenced by the approaches to, and perceived importance of, disability sport from some NGBs. Some of the NGBs, particularly smaller NGBs, are constrained by funding limitations, and decided to prioritise their 'bread and butter' (Respondent 7) - elite squads - rather than grassroots disability work. This is despite most NGBs being in receipt of Sport England funding to provide for disabled people ${ }^{7}$. Smaller NGBs, even for their elite work, can often rely on the NDSOs to find potential new participants for their sport, rather than recruit participants themselves. Thus, the commitment to mainstreaming from some NGBs is less apparent (Thomas and Smith 2009). This was the experience of one NDSO's relationship with a small NGB constrained by funding:

They're obviously focused on those athletes that are there already, but it then means they don't really have any funding to do anything at grassroots level, which is why they use the NDSO events and find them a crucial way to find new athletes. (Respondent 7).

Some of the NGBs, thus, exhibit approaches to grassroots sport which neglects and devalues the role of disabled people in their sport. Our interview data offered evidence that the importance of grassroots disability sport provision has been sidelined by some of these NGBs in favour of what they deem to be more important, namely their elite squads and non-disabled audience. The management of critical resources, in this case smaller NGBs, is compounded by the NDSOs' own internal and external resources, as 'there's a limited amount of funding to go round and we don't have any delivery money' (Respondent 3).

7 Sport England invested approximately $£ 91.5$ million into forty-two of the forty-six NGBs in receipt of 2013-17 whole sport plan funding (Sport England, n.d.). 
The prioritisation of non-disabled elite athletes and participants by some of the NGBs underlines some of the ableist cultures that exist within NGBs. The culture of inclusion has not been fully embedded within most NGBs, with most NGBs still viewing sport as being a domain of non-disabled people first and foremost:

It's just a slow process of changing things they've done differently for a long time. In a minority, as they often see it, it can take a lot of time. So it's a group they've never really provided for before, so they're learning. (Respondent 8).

I'm passionate about what I do, and believe in what I do, but the frustration is that you're trying to change hearts and minds. (Respondent 5).

The dependency of the NDSOs on NGBs for their involvement in increasing sport participation has caused frustration amongst some NDSOs:

...this happened to me only 3 or 4 weeks ago, talking to a Governing Body about 'what plans could we do for your sport?' I mean I'm still having those conversations now [emphasis], and we're near the end of the project, 2017, and it was very much, 'oh, we're writing our disability project now...we'll come back to you'. (Respondent $5)$.

Some of the NDSOs reported using the status and power of Sport England to increase the involvement of NGBs in disability participation:

Some of them $[\mathrm{NGBs}]$ were the big players and people that represented Paralympic sports as well, who were a bit more resistant. But that was fed back to Sport England and I wasn't the only NDSO who fed that back (Respondent 6).

The NDSOs are small organisations, employing less than 20 people and as low as one fulltime employee. They are not equipped as organisations to deliver sport participation 
opportunities nationwide. If the NGBs and CSPs did not enter into an exchange of resources then the NDSOs would still be able to function, but their delivery would be minor and local:

A lot of the NDSOs are either doing the work themselves to run activity, or doing it locally [emphasis] with a local [emphasis] NGB, or regional NGB, rather than a national, which then affects strategy, really, because you don't embed it into the organisation. (Respondent 5).

Historically, it was the NDSOs, rather than the NGBs, who often engaged in delivery work, frequently because of a lack of commitment to mainstreaming by some NGBs (Thomas and Smith 2009). The NDSOs' role is now of a strategic enabling function, whereby the NDSOs are able to use their expertise to advise and influence providers such as NGBs. Adjusting to this positon in the sport participation system has been one of the challenges for the NDSOs:

It's quite a culture shock to suddenly go into this completely different relationship with a different view of what you would do. (Respondent 2).

The NDSOs have thus had to adapt their outputs to suit the needs of a key supplier of a resource, Sport England, in order to be able to access critical funding.

Notwithstanding the historic position of NDSOs as deliverers of sport participation, the NDSOs' outputs are made up to a strong degree regarding the involvement of NGBs and CSPs cooperating and opening their participation networks to athletes the NDSOs cater for. The NGBs and CSPs are thus critical to the NDSOs because their position in the disability sport sector is not to deliver, and they lack the resources to do so nationally in any case.

\section{Limited resources of the charity can be a challenge}

The majority of the NDSOs are constrained by the resources available to them, with most limited in the internal and external resources they can utilise. It is important to note that many 
of the NDSOs were founded by volunteers because they, or their family members, had not been able to access sport participation to suit their needs: '.. disability sport is often generated from frustration; people that have tried mainstream sport and not been very successful, so set up their own' (Respondent 8). Thus, the volunteers who established the NDSOs did so out of enthusiasm and a desire to provide opportunities for participation, and might therefore not have had the necessary business skills needed to govern the organisation (Respondent 8). It is not surprising, therefore, that there was a lack of professional structures in place at some of the NDSOs before the 2012 Paralympics, and poor governance and financial management was not uncommon (Respondent 1; Respondent 5). With the increased focus on, and development of, disability sport since the 2012 Paralympic Games, the NDSOs have been able to improve the management of the organisation and become more professionalised organisations:

\author{
We've done really well. When I took over [Name of NDSO] (in 2011) we had less \\ than three months running costs in the bank, I had one member of staff, and I was \\ working two days a week because they couldn't afford a CEO full-time. I now have \\ 10 staff, I have just under a year's running costs in the bank. (Respondent anonymised \\ to maintain confidentiality).
}

It's driven some more money into their organisations. It's driven more volunteers to help support them. The majority of them are in a far more sustainable position than they ever were... so you now have these organisations that are professional bodies. (Respondent 9).

The NDSOs have become much more professional in the management of the charity and have grown the size of the organisation, aided by the need to professionalise to receive Sport England funding (Froelich 1999), but the internal capacity of the organisation can be a 
challenge to growing the charity further. LimbPower, for example, has one full-time member of staff and is constrained in being able to limit its dependency on the Sport England grant it receives. UK Deaf Sport, for example, hired the services of a company to seek expertise in how to achieve a greater range of income generation sources, as it too is dependent on Sport England's grant (UK Deaf Sport 2016). To combat a lack of knowledge of how to generate diverse income sources, a number of the NDSOs have recruited and financed fundraising positions within the organisation. There has also been a deliberate attempt to focus on increasing the revenue generation of the organisation, such as one NDSO which used 'a grants profile that profiles our fundraising, where those grants are now, [and] how they're used' (Respondent 1). The emphasis on improving the revenue potential of the charity is a recognition of the potential dangers of being too dependent on one source of finance (Bingham and Walters 2013; Carroll and Stater 2008), and an acknowledgement of the tough economic conditions for charities as a result of austerity measures. In addition, this tactic is a way of growing the organisation and to help meet its organisational objectives, as being strategic with regards to revenue generation is important in the operation of a non-profit organisation (Misener and Paraschak 2006).

The challenges faced by the NDSOs have been both internal and external. There is no doubt the austerity measures introduced by the UK government have created a difficult environment for the NDSOs to grow (NCVO 2015), with competition for funding increasingly fierce.

Despite the austere environment, however, Sport England has increased the amount of funding it has provided to the NDSOs, and the NDSOs have increased the number of services offered and staff they have been able to recruit. The tactics used to achieve this is the focus of the next section.

\section{Tactics}




\section{Alliances and financial reserves reduce dependency on critical resources}

The RDT suggests alliances may be a method for an organisation to reduce its dependency on a resource (Hillman et al. 2009; Malatesta and Smith 2014). Partnerships can be an important way of improving the human resources of the organisation and acquisition of critical resources (Misener and Doherty 2009). The formation of alliances has been a tactic adopted by some of the NDSOs. The creation of the English Learning Disability Sport Alliance can be viewed “... as mechanisms for achieving interfirm coordination” (Pfeffer and Salancik 2003, p. 161). The English Learning Disability Sport Alliance was formed between Mencap Sport and Special Olympics GB in November 2011, and has enabled a unified voice for learning disability sport (Special Olympics Great Britain n.d.). This alliance facilitated the two NDSOs to pool their resources together and make it easier for the NGBs to engage with the NDSOs, than might have been the case if the alliance had not been formed (Malatesta and Smith 2014). This alliance has thus enabled Mencap Sport and SOGB to manage their critical resources. For example, the SOGB participant explained one of the ways in which the alliance has helped the organisation:

One of the things we developed... was a learning disability in sport workshop, and the key message that we put over in that is, [if] you create a welcoming environment and you have good coaches, you are $90 \%$ of the way to being able to do everything you need to do to get someone with a learning disability come into your club, being coached and enjoying and benefitting from that experience. (Respondent anonymised to maintain confidentiality)

On their own, SOGB may have struggled to have made as much headway as they have with NGBs, highlighting the beneficial nature of the alliance to the management of SOGB's resources. A Sensory Impairment Sports Alliance between British Blind Sport and UK Deaf 
Sport was agreed during the 2013/14 financial year. This alliance intended to share resources between the two organisations and to improve the participation rates of both impairment groups (anonymous personal communication, 18 November 2016). Again, the driving force behind the alliance was a management of critical resources, as these two NDSOs represent the impairment groups with the lowest sport participation rates (anonymous personal communication, 18 November 2016). The alliance, it is argued, is a way of both NDSOs to manage their resources and to reduce dependency (Malatesta and Smith 2014). In addition to the aforementioned alliances, a memorandum of understanding between CP Sport and WheelPower was agreed in July 2013, with the aim of improving the partnership and collaboration between both NDSOs. Consistent with Malatesta and Smith's (2014) research on alliances, the formation of alliances and memorandum of understandings present a more powerful voice and help to persuade organisations to work with the NDSOs to increase sport participation opportunities. NDSOs have worked much more collaboratively in the last four years than was the case before (Respondent 6), as there has been a realisation that a collective voice is more powerful than a series of disparate voices. Campaigns like 'Together We Will' (EFDS 2016) present the message of the NDSOs more effectively than would have been the case on their own, and increases the credibility of the message. The forming of alliances has also benefitted some of the NDSOs in their application for funding grants (Respondent 6). By forming an alliance, the NDSO can offset some of the individual weaknesses of their organisations, through increased access to resources (such as financial, structural, and knowledge-based resources), making them more attractive to funders and partners, than might have been the case if the organisations were operating individually. Alliances have been beneficial to the NDSOs' organisational missions and have extended their reach, but one respondent noted a reluctance to form a larger physical impairment alliance because of a fear of less autonomy and possible funding reduction: 
I think there's a bit of reticence, because people are worried that if we do that, then would Sport England not turn round and say, 'why are we funding four of you, should we not fund one?'. (Respondent 5).

It is not uncommon for alliances between non-profit organisations to provoke the worries espoused by the respondent, as these organisations are still competing for similar resources as well as aiming to increase their organisational reputation (Babiak and Thibault 2009). Notwithstanding the challenges to extending the alliances further, increased collaboration and formation of alliances are methods that have been used to reduce dependency of individual NDSOs on their critical resources.

Another tactic used by the NDSOs is to have a financial reserves policy (Respondent 1; Respondent 4; Respondent 6). The NDSOs differ in the make-up of their reserves, in terms of how much cash they hold in the bank, but this policy acts as a safety-net for the NDSOs in case some years are less successful financially than others. It has been the intended aim of some of the NDSOs to build up their reserves in order to ensure a more financially healthy organisation:

I'm not saying we're in a delicate state, but I always would like to see a little bit more sitting in our reserves. (Respondent 1).

It has been difficult for some of the NDSOs to increase their reserves, but this is not unique to the NDSOs. This is borne out by the fact that the UK charity sector's total reserves dropped from $£ 54.1$ bn in $2010 / 11$ to $£ 44.5$ bn in $2012 / 13$, before arresting the decline to record total reserves of $£ 49.6 \mathrm{bn}$ in $2014 / 15$ (NCVO 2017). The reserves, therefore, enable the NDSOs to keep the charity functioning for a certain period of time if the income of the charity is reduced or withdrawn. In addition, the financial reserves policy provides a financial 'buffer' for the charity during austere times, when access to resources can be difficult to acquire. The 
policy of having financial reserves also enables the NDSOs to reduce some of the dependency on single grants, such as that awarded by Sport England.

\section{Acquiring knowledge as a resource}

Knowledge can be an important factor in the control over a resource (Pfeffer and Salancik 2003), and the NDSOs have attempted to increase knowledge of their target population through research and insight. Some NGBs lack detailed knowledge of how to cater for disabled people:

Until this last Whole Sport Plan cycle [2013-2017], they weren't actually given set targets for disability, not all of them. And now I think 40 out of 46 have a target. So it's a group they've never really provided for before, so they're learning. (Respondent 8).

The NDSOs do have the expertise of sport for their respective impairment groups, and it is one of the methods used by the NDSOs to increase their influence and power relations with partners:

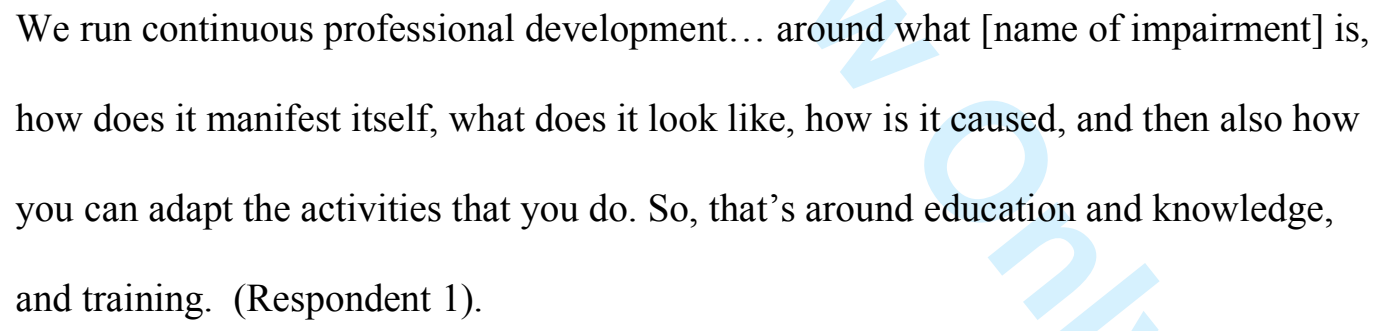
how does it manifest itself, what does it look like, how is it caused, and then also how you can adapt the activities that you do. So, that's around education and knowledge, and training. (Respondent 1).

...We offer insight and research into sport for [specific impairment] people, which we then share with all our related parties, which is NGBs, third-sector organisations. (Respondent 6).

Indeed, the specific purpose of the NDSO is to enable and identify participants for organisations such as NGBs and CSPs (Respondent 6; Respondent 8; Respondent 9). 
The NDSOs commission and help produce a number of research and insight publications in order to be equipped with enhanced understanding as to the behaviour of their consumer group. Surveys, desk research, in-depth interviews, and focus groups are some of the methods that the NDSOs have used to increase their knowledge. For example, BBS has produced sport specific resources to enable coaches to support the participation of visually impaired athletes. UKDS undertook extensive mixed methods research in order to understand in more detail the sport participation of their population group. This enables UKDS to take this knowledge to providers and make it easier for partners to provide opportunities for athletes with hearing impairments:

This was giving them that ability to say, 'you now know what you didn't know, therefore what's stopping you now from doing that?' You know, you've got to give me a better reason, than 'we don't think there's enough people out there because we've tried it before'. That quite clearly states there is, so now how are we gonna work together? How are we gonna do this? (Respondent anonymised to maintain confidentiality).

In addition to specific research and insight projects carried out by the NDSOs, six of the NDSOs commissioned 'Active Beyond Education?' in order to understand the experiences of young disabled people in sport and physical activity after they have finished education. These examples demonstrate some of the ways in which the NDSOs have attempted to increase their ability to control and distribute valued resources to partners.

The NDSOs play an important role in identifying potential participants for the NGBs to target. Gaining access to this population would be difficult for the NGBs and CSPs to achieve without the guidance and expertise of the NDSOs. Generation of knowledge as a resource is thus a significant activity for the NDSOs in their management of external resources. This 
helps to increase the mutual dependence of partners on the NDSOs for the knowledge and insight that NDSOs can provide, whilst also reducing the power imbalance between NDSOs and partners which the NDSO engages with for its critical resources (Casciaro and Piskorski 2005). This is achieved through the NDSOs' control of a resource, knowledge of their audience, that the NGBs and CSPs require to adequately fulfil their disability grassroots participation work (Pfeffer and Salancik 2003).

\section{What influence has austerity had on the resource dependency of the NDSOs?}

Acquiring funding has been a challenge for the NDSOs, with many charities competing for the same funding (Respondent 1; Respondent 8). Without austerity, the internal resources of the NDSOs are such that funding would still probably be a challenge for the NDSOs to obtain. But it is possible that there would be more funding sources available and potentially more corporate donors willing to invest in the NDSOs. Indeed, income from the government in the voluntary sector reached a high of $£ 15.2$ billion in $2009 / 10$, but has subsequently dropped below that figure (NCVO 2015). Since the 2012 Paralympic Games there has been an increased emphasis on disability sport by Sport England, and much more investment into developing the system has occurred than was the case prior to the Paralympic Games (Sport England n.d.). The NDSOs have benefitted from this increased monetary and political focus on disability sport (Respondent 2), which has aided their efforts to grow. Without the London 2012 Paralympic Games, austerity measures may have had a more negative effect on the growth potential of NDSOs.

Whilst NDSOs, as organisations, have been able to grow amid a time of austerity, austerity has negatively affected one of the critical resources they rely on. Brown and Pappous (2017) found that some disabled people were fearful of being seen to be too active in case they were accused of being a 'benefit scrounger' and subsequently have their benefits taken away. For 
the NDSOs, if some disabled people disengage or do not attempt sport participation because of a fear of losing benefits, this has a negative impact on the NDSO's ambition to increase sport participation. The changes to the disability benefits system was part of the Coalition and Conservative government's austerity measures, and the government have helped to fan the flames for the negative media portrayal of disabled people as benefit scroungers (Briant et al. 2013). Thus, austerity has had an impact on one of the critical resources of the NDSO, disabled people, and this has been a challenge for the NDSOs to overcome. The government has supported the growth of the disability sport system and organisations such as the NDSOs through their increased political and monetary focus. The government, however, has also potentially impeded some of that growth through the removal of disability benefits for some disabled people, reducing the capability of some disabled people to participate, and for aiding some of the negative media coverage of disabled benefit claimants.

\section{Conclusion}

This research has enhanced our understanding of how NDSOs, an important organisation in the disability sport system, have managed their resources during a time of austerity. Austerity has added to the competition for funding and has forced some of the NDSOs to review their fundraising and funding application procedures, in order to deal with the increased competition for funding from other charities. The changes to the disability benefits system as part of the austerity agenda has added to the challenges facing the NDSOs in attempting to increase the sport participation of disabled people (Brown and Pappous 2017). Despite the backdrop of austerity, the NDSOs have been able to increase the services they offer. This research found public funding for the NDSOs from Sport England has increased since 2011, despite austerity measures in the UK during this time period, with the hosting of the London 2012 Paralympic Games an important factor in the increased investment. The NDSOs have experienced increased demand for their services from NGBs and CSPs since 2011, and have 
developed additional resources to cater for the increased demand. The development of the NDSOs into professional strategic organisations enables the NDSOs to have increased influence and power in relationships with providers (Casciaro and Piskorski 2005), and in the management of grassroots sport for disabled people (Thomas and Smith 2009), then was the case prior to 2011. The influence of the London 2012 Paralympic Games in the development and growth of the NDSOs cannot be understated.

Total income for the NDSOs have largely increased, but so too has the total expenditure for achieving organisational growth. The finances of the NDSOs illustrate the tough economic conditions within which they operate. Funding from Sport England accounted for a significant proportion of the total income for a number of the NDSOs. Whilst there are no indications of a change in emphasis or focus on disability sport at this stage, a diversification of revenue sources and a reduction in the proportion of revenue made up by Sport England funding should be explored to reduce potential revenue volatility (Bingham and Walters 2013; Carrol and Stater 2008). 


\section{References}

Babiak, K. and Thibault, L., 2009. Challenges in Multiple Cross-Sector Partnerships.

Nonprofit and Voluntary Sector Quarterly [online], 38 (1). Available from:

10.1177/0899764008316054 [Accessed 25 August 2017].

Beatty, C. and Fothergill, S., 2015. Disability Benefits in an Age of Austerity. Social Policy Administration [online], 49 (2). Available from: 10.1111/spol.12117 [Accessed 5 September 2016].

Bingham, T. and Walters, G., 2013. Financial Sustainability Within UK Charities:

Community Sport Trusts and Corporate Social Responsibility Partnerships. Voluntas:

International Journal of Voluntary and Nonprofit Organizations [online], 24 (3). Available from: 10.1007/s11266-012-9275-z [Accessed 10 December 2016].

Blyth, M., 2013. Austerity: The History of a Dangerous Idea. New York: Oxford University Press.

Briant, E., Watson, N., and Philo, G., 2013. Reporting disability in the age of austerity: the changing face of media representation of disability and disabled people in the United

Kingdom and the creation of new 'folk devils'. Disability \& Society [online], 28 (6).

Available from: http://dx.doi.org/10.1080/09687599.2013.813837 [Accessed 5 September 2016].

Brinkmann, S. and Kvale, S., 2015. Interviews: learning the craft of qualitative research interviewing. 3rd ed. Los Angeles: SAGE.

Brittain, I. and Beacom, A., 2016. Leveraging the London 2012 Paralympic Games: What Legacy for Disabled People? Journal of Sport and Social Issues [online], 40 (6). Available from: 10.1177/0193723516655580 [Accessed 7 June 2017]. 
Brown, C. and Pappous, A., 2017. 'We weren't asking the right questions': Learning sport participation leveraging lessons from the London 2012 Paralympic Games. [Unpublished manuscript].

Carroll, D. A. and Stater, K. J., 2008. Revenue Diversification in Nonprofit Organizations: Does it Lead to Financial Stability? Journal of Public Administration Research and Theory [online], 19 (4). Available from: https://doi.org/10.1093/jopart/mun025 [Accessed 18 December 2016].

Casciaro, T. and Piskorski, M. J., 2005. Power Imbalance, Mutual Dependence, and Constraint Absorption: A Closer Look at Resource Dependence Theory. Administrative Science Quarterly [online], 50 (2). Available from: http://www.jstor.org/stable/30037190 [Accessed 5 September 2016].

Cerebral Palsy Sport, 2016. Annual Report of the Trustees For the Year Ended 31 December 2015. Nottingham: Cerebral Palsy Sport. Available from: http://www.cpsport.org/wpcontent/uploads/2015/02/CP-Sport-Trustees-Report-Year-End-2015-Final.pdf [Accessed 10 November 2016].

Charity Commission, n.d. Search for a registered charity. Available from: http://beta.charitycommission.gov.uk/ [Accessed 10 November 2016].

Cross, M., 2013. Demonised, impoverished and now forced into isolation: the fate of disabled people under austerity. Disability \& Society [online], 28 (5). Available from: http://dx.doi.org/10.1080/09687599.2013.808087 [Accessed 5 September 2016].

Crow, L., 2014. Scroungers and Superhumans: Images of Disability from the Summer of 2012: A Visual Inquiry. Journal of Visual Culture [online], 13 (2). Available from: 10.1177/1470412914529109 [Accessed 5 September 2016]. 
Emerson, R. M., 1962. Power-Dependence Relations. American Sociological Review

[online], 27 (1). Available from: http://www.jstor.org/stable/2089716 [Accessed 5

September].

English Federation of Disability Sport., 2014. Sport England invests a further $£ 2.1$ million to get more disabled people playing sport. Available from: http://www.efds.co.uk/news/876sport-england-invests-a-further-21-million-to-get-more-disabled-people-playing-sport [Accessed 17 June 2016].

English Federation of Disability Sport, 2016. Together We Will [online]. Available from: http://www.efds.co.uk/together [Accessed 10 December 2016].

Froelich, K. A., 1999. Diversification of Revenue Strategies: Evolving Resource Dependence in Nonprofit Organizations. Nonprofit and Voluntary Sector Quarterly [online], 28 (3).

Available from: http://journals.sagepub.com/doi/abs/10.1177/0899764099283002 [Accessed 10 December 2016].

Hillman, A. J., Withers, M. C., and Collins, B. J., 2009. Resource Dependence Theory: A Review. Journal of Management [online], 35 (6). Available from: http://journals.sagepub.com/doi/abs/10.1177/0149206309343469 [Accessed 14 December 2016].

King, N., 2014. Local authority sport services under the UK coalition government: retention, revision or curtailment? International Journal of Sport Policy and Politics [online], 6 (3). Available from: http://dx.doi.org/10.1080/19406940.2013.825873 [Accessed 10 October 2016].

Krugman, P., 2015. The case for cuts was a lie. Why does Britain still believe it? The austerity delusion. The Guardian, 29 April [online]. Available from: 
https://www.theguardian.com/business/ng-interactive/2015/apr/29/the-austerity-delusion [Accessed 5 September 2016].

Kvale, S., 2007. Doing Interviews. London: SAGE.

Lowndes, V. and Gardner, A., 2016. Local governance under the Conservatives: superausterity, devolution and the 'smarter state'. Local Government Studies [online], 42 (3). Available from: http://dx.doi.org/10.1080/03003930.2016.1150837 [Accessed 5 September 2016].

Malatesta, D. and Smith, C. R., 2014. Lessons from Resource Dependence Theory for Contemporary Public and Nonprofit Management. Public Administration Review [online], 74 (1). Available from: 10.1111/puar.12181 [Accessed 5 September 2016].

Misener, K. and Doherty, A., 2009. A Case Study of Organizational Capacity in Nonprofit Community Sport. Journal of Sport Management [online], 23 (4). Available from: 10.1123/jsm.23.4.457 [Accessed 25 August 2017].

Misener, K. and Paraschak, V., 2006. Fundraising capacity in Canadian national sport organizations: Relationship-building and gender. Third Sector Review [online], 12 (2). Available from: http://search.informit.com.au/documentSummary;dn=200707855;res=IELAPA [Accessed 25 August 2017].

NCVO (The National Council for Voluntary Organisations), 2015. UK Civil Society Almanac 2015/ Income from government [online]. Available from:

https://ata.ncvo.org.uk/a/almanac15/government/ [Accessed 5 September 2016]. NCVO (The National Council for Voluntary Organisations), 2017. UK Civil Society Almanac 2017/ Assets and Reserves [online]. Available from: 
https://data.ncvo.org.uk/a/almanac17/assets-and-reserves-2/\#Reserves [Accessed 25 August 2017].

Pappous, A., Marcellini, A., and de Léséleuc, E., 2011. From Sydney to Beijing: the evolution of the photographic coverage of Paralympic Games in five European countries. Sport in Society [online], 14 (3). Available from: http://dx.doi.org/10.1080/17430437.2011.557271 [Accessed 5 September 2016].

Parnell, D., Millward, P., and Spracklen, K., 2015. Sport and austerity in the UK: an insight into Liverpool 2014. Journal of Policy Research in Tourism, Leisure and Events [online], 7 (2). Available from: http://dx.doi.org/10.1080/19407963.2014.968309 [Accessed 10 October 2016].

Pfeffer, J. and Salancik, G. R., 2003. The External Control of Organizations: A Resource Dependence Perspective. Stanford, California: Stanford University Press.

Pring, J., 2015. Confirmed! UN is investigating UK's 'grave violations' of disabled people's rights. Disability News Service, 11 September [online]. Available from: http://www.disabilitynewsservice.com/confirmed-un-is-investigating-uks-grave-violationsof-disabled-peoples-rights/ [Accessed 5 September 2016].

Saldaña, J., 2016. The Coding Manual for Qualitative Researchers. 3rd ed. London: SAGE. Special Olympics Great Britain, 2016. Special Olympics Great Britain Trustees' Annual Report and Accounts For the year ended 31st December 2015 [online]. London: Special Olympics Great Britain. Available from: http://apps.charitycommission.gov.uk/Accounts/Ends29/0000800329_AC_20151231_E_C.p df [Accessed 10 November 2016]. 
Article accepted for publication in the International Journal of Sports Policy and Politics, 19/10/2017.

Special Olympics Great Britain, n.d. Our Alliances [online]. Available from:

http://www.specialolympicsgb.org.uk/our-alliances [Accessed 17 June 2016].

Sport England, 2011. £2.6 million funding boost to get more disabled people playing sport

[online]. Available from: http://www.wired-gov.net/wg/wg-news-

1.nsf/article/2.6+million+funding + boost + to + get + more + disabled + people + playing + sport +090

72011112500?open [Accessed 17 June 2016].

Sport England, n.d. Disability Infographics [online]. Available from:

https://www.sportengland.org/our-work/disability-sport/disability-infographics/ [Accessed 17 June 2016].

Thomas, N. and Guett, M., 2014. Fragmented, complex and cumbersome: a study of disability sport policy and provision in Europe. International Journal of Sport Policy and Politics [online], 6 (3). Available from: http://dx.doi.org/10.1080/19406940.2013.832698 [Accessed 17 June 2016].

Thomas, N. and Smith, A., 2009. Disability, sport and society: an introduction. London: Routledge.

UK Deaf Sport, 2016. UK Deaf Sport (a charitable company limited by guarantee) Trustees' report and unaudited accounts for the period ended 31 January 2016 [online]. Worcester: UK Deaf Sport. Available from: http://ukdeafsport.org.uk/wpcontent/uploads/2016/10/UKDS-Trustees-report-and-unaudited-accounts-for-period-end31.1.2016.pdf [Accessed 10 November 2016].

UK Deaf Sport, n.d. AGM Minutes and Presentations [online]. Available from: http://ukdeafsport.org.uk/agm-minutes-and-presentations/ [Accessed 10 November 2016]. 
Ulrich, D. and Barney, J. B., 1984. Perspectives in Organizations: Resource Dependence, Efficiency, and Population. The Academy of Management Review [online], 9 (3). Available from: http://www.jstor.org/stable/258287 [Accessed 5 September 2016].

Walker, C. M. and Hayton, J. W., 2016. Navigating austerity: balancing 'desirability with viability' in a third sector disability sports organisation. European Sport Management Quarterly [online]. Available from: http://dx.doi.org/10.1080/16184742.2016.1210190 [Accessed 10 October 2016].

Wolbring, G., 2012. Expanding ableism: Taking down the ghettoization of impact of disability studies scholars. Societies [online], 2 (3). Available from: http://www.mdpi.com/2075-4698/2/3/75 [Accessed 7 June 2017].

Wood, C., 2012. “For disabled people, the worst is yet to come..." Destination Unknown: Summer 2012. DEMOS [online]. Available from:

https://www.demos.co.uk/files/Destination_Unknown_Summer_2012__web.pdf?1340294386 [Accessed 5 September 2016]. 